\title{
Herd Agency
}

\section{Rethinking Herd-Herder Relations in Mongolia and Qinghai, China}

\author{
Dulam Bumochir \\ Professor of Anthropology, Department of Anthropology \& Archaeology, \\ National University of Mongolia, Ulaanbaatar, Mongolia \\ bumochir@num.edu.mn

\section{Byambabaatar Ichinkhorloo} \\ Senior Lecturer, Department of Social Anthropology and Cultural Studies, \\ the University of Zurich, Zurich, Switzerland \\ byambabaatar.ichinkhorloo@uzh.ch,bimbamn@gmail.com
}

\author{
Ariell Ahearn \\ Lecturer, School of Geography and the Environment, \\ University of Oxford, Oxford, UK \\ ariell.ahearn@ouce.ox.ac.uk
}

\begin{abstract}
In this article, we draw upon ethnographic fieldwork conducted in Mongolia and China to develop understandings of herd-herder (mal-malchin) relations further. We focus primarily on horse-herding practices and related divisions of labour, and the three concepts of herd intuition (zön), serenity (taa) and fortune (buyan, khishig, zaya), to present additional interpretations of human-animal relations in Mongolia. Through this exploration, we develop the concept of herd agency and examine how it relates to specific horse-herding knowledge and techniques, as well as the cosmological significance of human-animal relations. All three concepts reveal the importance of cosmological agents with herd-herder relations. We conclude by emphasising the changing nature and politics of human-animal relations in these regions.
\end{abstract}

\section{Keywords}

herd - herder relations - herd agency - horse herding - labour division - animal autonomy 
This paper examines herder-herd relations mainly in the case of the horse in Mongolia and in Qinghai, China, and develops the concept of herd agency, focusing on three interlinked concepts which feature in herder descriptions of working with herds: the herd's intuition (malyn zön), serenity (taa or taatai baidal), and fortune (buyan, khishig and zaya). By introducing the concept of herd agency and showing how herders acknowledge herd agency, this paper sheds light on an alternative elaboration of human-animal coexistence (Fijn 2011; Stépanoff et al. 2017). In this paper, we aim to contribute to the classical theory of human-animal coexistence by engaging with literature on animal domestication (Cassidy \& Mullin 2007) and the extent to which pastoralism represents human domination and control over herds (Ingold 1994).

The first discussion we engage with argues that in Mongolia and North Asia, 'indigenous techniques tend to rely preferentially on animal autonomy and a herd's capacity to feed and protect itself' (Stépanoff et al. 2017: 57). Although explicitly presenting examples which move beyond the product-consumer relation of herds and herders, Charles Stépanoff and colleagues critique the idea of symbiosis, that 'herding communities are based on a dyadic relation between reciprocal dependence between humans and animals' (2017:58) and introduce the idea that in North Asian mobile grazing some herd animals have 'seasonal freedom', where they are autonomous to the extent that pastoralist groups show a reluctance in shooting wolves to protect them. They argue that existing anthropological theories, such as those discussing producer and product (Hamayon 1990: 327), human domination (Descola 2013; Ingold 1994), and the notion of 'symbiosis' (Beach \& Stammler 2006; Takakura 2015; Vitebsky \& Alekseyev 2014), more fully describe human-animal relations of sedentary farms with fixed structures and supplementary fodder. They propose an alternative interpretation, 'that North Asian herding systems maintain a balance between two possibly conflicting tendencies: animal autonomy and animals' disposition to engage in cooperative interaction with humans' (Stépanoff et al. 2017: 58). They present different examples to show that 'herders do not treat their animals as consumable goods [and objects] over which they have an absolute right of life and death' (2017:59). This claim is valuable in reminding us that herding practices of mobile pastoralists in North Asia illustrate that herds are not valued only as products, goods and objects for the purposes of mass production through containment and everyday fodder provision. The second discussion emphasises that these practices are not mutually exclusive: herds can be highly mobile, spiritually valued and part of wider cosmological beliefs while still bought and sold on markets (Beach \& Stammler 2006). This idea 
was nicely captured in a recent article on hippophagy entitled 'We eat whom we love' (Peemot 2017). ${ }^{1}$ Building on Tim Ingold's (1994) work on herd-human societies and his encouragement to re-think the subject-object, we explore the enmeshment of herds and herders in Inner Asia through the concepts of herd serenity, intuition and fortune.

While Stépanoff et al.'s paper does present insightful descriptions of humananimal relations with reference to North Asia, we argue that the interpretation of the autonomous degree of animal control which may be the case in Siberia fails to capture two focal points in herd-herder relations. First, the analysis of 'animal autonomy', as well as the other existing theories on human-animal relations in North and Inner Asia, misses the indigenous understanding of herd agency. We argue that herd-herder relations among Mongols are not about animal autonomy, but about herders' recognition of herd agency. We also argue that the notion of herd agency is in some ways different from animal agency. Unlike those who discussed animal agency (Heikkinen et al. 2011; Horstkotte et al. 2017; Philo \& Wilbert 2000; Steward 2009), we posit that herd agency is not only about individual herd animals, but also about the agency of a group of herd animals as a collective agent. Also, unlike many of those authors, we focus not on animal agency per se; instead we focus on the indigenous herders' depiction of herd agency and how such depictions shape herd-herder relations.

In the context of herding, zön is a complex term that is often regarded as meaning their innermost, natural and biological, intuition or instinct, which the herd reveals through their behaviour. Herders are required to acknowledge and treat herd animals accordingly while herding and grazing. In this sense, $z o ̈ n$ is a form of herd agency acknowledged in the herding technique zöngöör $n$ mallakh [to herd following animals' intuition], to provide serenity [taavaar $n$ mallakh, or to herd following comfort of the $\mathrm{mal}$ ]. In this context, herders contemplate that herding should be reliant on herd animals' kind, size, age, gender, behaviour, diet, health, etc. to provide serenity based on their zön. Moreover, in Mongolian, in the context of herding, buyan is a Buddhist concept, which indicates karmic consequence of merit, while khishig indicates fortune (see also Empson 2011; High 2017; Humphrey \& Ujeed 2012) and zaya indicates fate and destiny. In this context, to keep the buyan khishig or buyan zaya (or zaya buyan) of herds tegsh [balanced] and/or dü̈̈ren [full], herders practice different customs and rituals. Herders believe that the herd is khöröngö [capital] and bayalag [wealth], and the source of all other forms of wealth and prosperity in

1 Some herders in Mongolia sell beloved herd animals in order not to eat them. Mongols in Qinghai do not eat horse. They consider hippophagy a serious betrayal to herders' most loyal mate (for hippophagy, see also Marchina et al. 2017: 176). 
the herding way of life. The concepts and related practices of herding through herd intuition for its serenity to ensure the fortune share a common factor. Besides the herd agency, these practices also bring in cosmological agents as participants or mediators in herd-herder relations, including Buddhist deities and land masters/spirits. Therefore, the term $\mathrm{mal}$ [herd] as used by herders indicates a type of relation where household and herd agencies are intertwined in spiritual and economic dimensions and includes mediation by cosmological agents.

Second, Stépanoff et al. use the concept of animal autonomy to argue that herders do not treat herd animals as the types of 'consumable goods' and 'products' found in industrial farming. We argue that herders do not treat herd animals as the types of goods and products, not because herders consider herd animals autonomous, but because herders consider herd animals as types of sources of wealth and prosperity. The term mal in Mongolian is a word with a Turkic origin referring to capital (khöröngö) and wealth (bayalag) (Nadelyaev et al. 1969: 365), and its verb form mallakh means not only to herd animals, but also to care for such capital and wealth. The practice of branding horses, for example, indicates a form of ownership or association with a particular family (Waddington 1974). The folk literature of Mongols in Qinghai, for example, depicts livestock as pastoralists' erdeni, which means a jewel and treasure (Luta 1986: 94). The same idea even appears in the constitution of Mongolia, declaring that 'livestock is the wealth of nation that should be protected by the state' (Mal süreg bol ündesnii bayalag bögööd töriin khamgaalaltand baina) (Bügd Nairamdakh Mongol Ard Ulsyn Ardyn Ikh Khural 1992, Chapter 5, Article 5.5), which was already apparent during socialism. During socialism J. Sambuu (1956) argued that livestock are not only the source of livelihood for people but also the backbone of the national economy (for national economy, see also Bumochir 2020).

For two reasons, materials we present in this paper focus on horse herding. First, the term human-animal relations is too broad and generic. For this reason, we prefer to use the term herd ( $\mathrm{mal}$ ) and herder (malchin). To be more precise, among herders who can be specialised in herding, different species build different relations; we take the horse herder and horse herd as an example to show the diversity and changing nature of herd-herder relations. Second, as we have seen in the above discussion, our focus on herd agency in this paper in some ways responds to Stépanoff et al.'s (2017) notion of animal autonomy with a particular focus on horse herding, because according to Stépanoff et al. the horse is more autonomous compared to other species.

The first two empirical sections of the paper, therefore, focus on horse herding, based on fieldwork conducted in Khentii, Arkhangai and Dundgovi 
aimags, where Byambabaatar Ichinkhorloo conducted fieldwork in 2013, 2014 and 2019, as well as Bayanbulag and Gurvanbulag sums, Bayankhongor aimag, where Dulam Bumochir and Ariell Ahearn conducted fieldwork in 2013. The final empirical section brings in material from Qinghai, China, where Bumochir conducted fieldwork in the early 2ooos. Although content in all three sections overlaps, we attempt to shed light on intuition in the first section, on serenity in the second and on fortune in the third. The material within all sections is based on interviews and participant observation with local herders. A key caveat of the discussion is that, due to political and economic change, herding techniques and human-animal relations cannot be essentialised and are undergoing processes of change.

According to S. Badamkhatan ([1981] 2010), herder households in Mongolia during the Soviet period began to specialise in herding one species, which helped collectives to manage and implement payment systems through labour divisions. Due to the socialist practice of species specialisation, many households in the post-socialist period lacked horse-herding skills and knowledge (for ecological knowledge, see also Soma \& Schlecht 2018). When collectives collapsed in the early 1990s, herder households started to re-learn other herding techniques. After the 199os, in order to re-construct the 'traditional' (ulamjlalt) knowledge, many researchers in Mongolia produced books and handbooks on the subject (Balkhaajav 2016; Davaakhuu 2016; Erdenetsogt 1998; Sonompel 2021; Tomorjav \& Khurelbaatar 2017; Tserenkhand 2005). They all noted that in horse herding it is important to make horses familiar with different techniques. This section focuses on horse herding and training practices, labour divisions and the importance of zöngöör $n$ mallakh, or herding by intuition (of the herds). ${ }^{2}$

Each family herds different species of herd animals, or multispecies herds, but certain individuals often focus on a specific herd, such as horse herds. Horse herding requires physical strength; therefore this kind of herding is typically carried out by younger men, between the ages of 12 and 40. Otgonkhuu (aged 27) in Bayankhutag shared his experience about how he learned horse herding from other men:

2 This section presents Ichinkhorloo's interviews with herders in Bayankhutag sum, Khentii aimag, in 2019, Tariat sum, Arkhangai aimag, in 2014 and in Bayanjargalan sum, Dundgovi aimag, from 2013 to 2016. 
I learned horse riding at the age of seven and started to go herding horses with my father. I learned how to use a lasso at the age of seven and eight, and to catch one- or two-year-old horses with uurga [a lasso pole] at the age of thirteen and adult horses at seventeen. When I was smaller, at eleven to fifteen years of age, I also followed neighbouring akh nar [elder brothers/uncles] who herd horses.

Besides physical strength, horse herding requires a schedule that is different from other species of herds. Horse herders who were interviewed in Bayankhutag, Tariat and Bayanjargalan often get up before light around 4-5 AM in summer and 6-7 AM in winter and go to places where the horse herd has ventured, or spend the night with the herd (see also Badamkhatan [1981] 2010: 1014). During the night, horses graze and travel for about $5^{-10}$ kilometres, as long as there are no rainstorms, strong winds or blizzards. Herders should be able to predict where to find their horses, taking the weather during the night into consideration. Herders often calculate wind direction, pasture condition, water, where other households have moved and where their other livestock are grazing. In the morning, herders should find and direct herds back to the camp from around $10-20$ kilometres radius to a place around $5^{-10}$ kilometres from the encampment and water the horses. The herder then takes a few hours of rest, or sleep. In the afternoon, the herder directs horses to a fresh grazing area as planned and returns home around 5-11 PM. These tasks habituate the horses and they become accustomed to the herder, routine and place (nutag). According to Gantuya, aged 63 (a state-honoured ${ }^{3}$ horse herder who owns more than 1000 horses in Bayankhutag):

In the morning, I leave my horses and they go to drink water at the Kherlen river around 9-10 AM and return to one specific place, which is cooler with less flies in the summer time. Wherever they go to drink, even as far as $7-8$ kilometres away, they come to that place. They spend the day there. In the late afternoon, when they are hungry, I go there and direct them for grazing.

Herds are trained at a young age and socialised in particular ways, becoming used to particular places and routines (Fijn 2011). In such accustomed conditions, horses are often left unattended to rely on their zön for certain periods

3 Ulsyn avarga malchin ['champion herder of the country'] is a state honour begun in the Mongolian People's Republic (MPR). The President of Mongolia delivers this honour to skilled and knowledgeable herders who successfully increased the number of their herds. 
of time, in certain conditions, in certain places under the prediction and calculation of the herder. Khatanbaatar (aged 37), who is the son of a well-known herder Osgon, in Bayankhutag, defines zöngöör n mallakh as follows:

Herd animals adapt well in their nutag's [homeland] environmental settings. Herd animals become familiar with the surrounding places and do not stray far away. For example, horses, in such cases, they can be left unattended and not disturbed, relying on their zön [or attachment to a certain place]. But in autumn, when horses are left to follow their zön, they go against warm winds and become lost. In wintertime, they go through blizzards and become lost. During these times, herders should be careful herding.

S. Dulam's work on the horse's zön to return home and recognise the herder helps us to understand what Khatanbaatar means with zön here. According to S. Dulam (2013: 240-41), herd animals have zön for instance attached to its nutag, or accustomed places, as a result of habituation. Based on the reports of eyewitnesses, he presents a story about a Mongolian horse that returned home from Vietnam to Mongolia. In 1959, after the visit of the Vietnamese President Ho Chi Minh to the Mongolian People's Republic (MPR), Tsedenbal Yumjaa, the leader of the MPR, presented him with five different kinds of herd animals. On the way to Vietnam by train, while changing trains on the ChineseVietnamese border, one horse escaped to the mountains. In 196o, after about a year, the horse returned home to Mongolia. ${ }^{4}$

We cannot prove or disprove the former, but this is also echoed in Ahearn's 2016 fieldwork in regions affected by herder displacement from mining in the South Gobi. Camels and horses return to the places they were brought to by herders and have come to know. When herders are displaced to other nutags due to mining, many herder households explain that their herds will always go back to the former nutag and it requires a lot of work to re-train livestock to a new area. All of these stories suggest that horses have agency, or zön, to return home. Certainly, this is not the only thing horses do with their zön. According to herders, following their zön, horses do not mate with their offspring, they find herbs and minerals their body requires, and so on. Therefore, herders consider that relying on a herd's zön is one of the best techniques of herding.

4 Recently, a Mongolian film Khiimori [Wind horse] about a horse that returns home from Russia to Mongolia won the award for the Best Feature Film at San Diego International Film Festival. 
As explained above, the key term in horse herding is zöngöör $n$ mallakh, which means to herd by letting animals follow their own decision-making and intuition, by directing horses gently and letting them graze in their natural comfort $(t a a)$. In this section, we focus on the herd's taa that can be provided by acknowledging their zön. Apparently, this is the key technique to fatten herds in order to ond oruulakh, which means to pass the harsh winter (Ichinkhorloo 2011). Herders have to herd the livestock and keep them alive as these animals are live-stock. All herders that Ichinkhorloo interviewed expressed that livestock must be fattened to survive harsh winters'. When herds are in comfort then, according to Ichinkhorloo, Sandag (78), of Bayankhutag, said: 'It is bad to shout or yell and say curse words to disturb herd animals and one should avoid chasing them fast or to make sudden jerky movements. You have to be gentle and herd calmly. This is called taavaar $^{5} n$ mallakh.' Many older herders lament the increased frequency of the use of motorcycles for herding, for example, explaining that the loud noise and speed of the motorcycle disturbs herd animals (Fraser 2018) and is not as conductive to 'taavaar n mallakh'. This was also confirmed by many herders in Bayanjargalan, Dundgovi, such as Purev (65), who herds sheep and goats; Mungunkhuyag (34), herding horses; or Khurelkhuu (69) and his son (37). Some other herders also say that to provide taa in herding horses requires aligning with the horses' own tastes in grasses and pasture. In other words, horse herders should be familiar with their horses' choice of grass, pasture and other environmental conditions to provide taa. On the other hand, this herding technique to provide serenity relying on their intuition poses great risks of losing the herd, especially in the absence of the horse herder who has already developed a relation with the herd.

In summer 2013, during fieldwork in the northern regions of Bayankhongor aimag, in Bayanbulag sum, Bumochir and Ahearn first visited Jigjidsuren's family. On the way from Gurvanbulag to Bayanbulag, they met Boroo, Jigjidsuren's eldest son, a tough, gregarious young man with good hunting and herding skills. In 2013, they had more than 1000 livestock including yaks, horses, sheep and goats. Boroo, being the eldest adult son, was the main labour force in the family. His younger brother was studying Buddhist painting in Ulaanbaatar, another younger brother did seasonal work in Ulaanbaatar and his youngest

5 In this context, sometimes herders use the term zön for taa, which blurs the boundary between zön and taa. As herders claim, when herds follow their zön then for that much they can find comfort. 
sister was attending secondary school at the time. In 2008, Boroo had to join the year-long obligatory military service and left his parents and young siblings in Bayanbulag. He was the one in the family who took care of horses and completed most of the heavy herding tasks in the family. When Boroo was away, in early December, all 6o of their horses became lost. Boroo's father began a search. He checked places where their horses frequently graze and other places where he thought they might be. Jigjidsuren explained that the horse is an urt khöliin mal [livestock with a long leg] and travels far for grazing, which makes herding tasks difficult. To let horses move around as much as possible to graze and gain weight and survive the winter, Jigjidsuren left them without many restrictions (taavaar $n$ ).

We call this principle in herding horses the provision of serenity relying on their intuition, not on their autonomy, which is the translation of the indigenous Mongolian term. In this sense, they are under the herder's guardianship, for example, as we mentioned, prediction and anticipation of routes and places where horses can go and stay and how far they can go. Those predictions and anticipations do not involve leaving horses to graze entirely autonomously, but to provide horses with serenity under extended forms of direction. Boroo, as the one experienced and obliged to practise such a herding technique in the family, was in a better position than his old father to enable the horse herd to roam. In the absence of Boroo, Jigjidsuren could not travel too far to look for the missing horses and abandon the rest of the livestock with not enough manpower to look after them. In that sense relying on their zön, Jigiidsuren tried to let his horses experience serenity under his direction, including predicting and anticipating their movements and desires, but he failed and lost them. Jigjidsuren was confident that if Boroo were home he could have found them, which means that the relationship Boroo developed with the horse herd is different from Jigjidsuren's own relationship with them. Although Jigjidsuren stopped looking for his horses, he inquired with local people and visitors if they had seen them and to look out for them. He visited a local lama for divination, who told him that his horses were alive and healthy and would come back, which sounded unrealistic to Jigjidsuren. Such effort to find the missing horses demonstrates attempts actively to discover their whereabouts and to extend forms of care and control, and indeed to restrict pure forms of autonomy.

When some months had passed, Jigjidsuren despaired about his lost horses. After almost four months, Jigjidsuren saw his horses on the mountain near his winter camp and broke into tears. All of the horses were there except one, which was his brother's horse. As we discussed, he thinks the herd's zön attached to their homeland kept his horses in the nutag, or brought them back 
home. Therefore, Jigjidsuren believes that in herding reliance on zön actually works. Besides zön, he also said that 'khangai had been herding his horses' (khangai mallasan) or 'khangai 6 watched over his horses' while they were missing. Here, khangai is a complex term representing the environment and supernatural spirit masters. Pastoralism, on the other hand, is the herd-herder interaction with the khangai. For herders, the pastoral herd-herder relation does not act independently; instead the khangai shapes herd-herder relations by providing the conditions for both to live and survive. ${ }^{7}$ His statement means that the khangai was herding on his behalf, which can mean feeding, protecting and controlling the horses in his and Boroo's absence. For Jigjidsuren, the presence of khangai and its help in herding does not leave herds to roam on their own, autonomously. Rather there are multiple potential agents that can contribute to the guardianship of the herds. A similar idea can be seen in practices associated with maintaining/ensuring herd fortune.

To explain why and how almost all of his horses survived, Jigjidsuren made another interesting point, concerning malyn buyan khishig [karmic consequences or fortune derived from herds]. He thinks that it was due to a karmic consequence of malyn buyan khishig that the horses survived and returned safely to the household. He took their survival as an indication of the strong malyn buyan khishig that they have in the household. Herders curiously talk about mal $n$ ösdög ail which means a 'household whose livestock number increases no matter what happens' when they have a malyn buyan khishig. Even when the family is not hard-working, inexperienced or the climate is severe, families with malyn buyan khishig may still enjoy an increase in herd numbers. For example, in the case of the 6o missing horses, only one died, and the dead one belonged to Jigjidsuren's brother. Following this belief, herders try hard to keep their herd fortune tegsh and/or dü̈rren, to prevent livestock loss, increase

6 Khangai is a name of the mountain range in the Central West part of the country. More than referring to the particular mountain, people commonly use the term khangai to indicate their local mountains or the natural mountainous environment in general. The word also means open steppe and wild nature including plants and animals, environment and earth in general. Also, it is common for herders to use the word khangai for wolf.

7 Stépanoff et al.'s idea of landscape as an 'interspecific common ground' is similar to khangai. However, khangai does not just ensure the health of the pastures, but is itself actively involved in herding. 
the number of animals, and create wealth and prosperity, by respecting their herd animals and following specific rituals, including particular ceremonies and customs. According to this thinking, the herds and its associated fortune are the source of wealth and a prosperous life, which is an indigenous way to treat herd animals as live-stock, if not consumable goods and products.

This reasoning expands beyond the pastoral enterprise to the fortune of the entire family (ailyn buyan khishig) involving all other aspects of life (see Empson 2011). For many herders, having malyn buyan khishig enables all other forms of well-being and goodness, such as good health, success, fairness and blessings, etc. Therefore, possessing a large number of livestock is not simply a quantitative security to protect from the risks of uncertain pastoral practices, such as a loss of livestock in the $d z u d$ winter crisis, as some argue (Thrift \& Ichinkhorloo 2015). Instead, it is a comprehensive sign of holistic family prosperity and wealth.

Practices of Mongols in Qinghai bring additional material to the discussion of herd-herder relations. In Qinghai, many rural and urban families have a skull of an $\mathrm{ak} \mathrm{mal}^{8}$ [uncastrated herd animal] and/or setertei mal [consecrated herd animal], such as the head of a deceased stallion, bull, or ram, with beautifully decorated silver metal plates, placed on the wall opposite the door. In front of some are offerings of dairy products, candies, biscuits and fruit. Herders explain that when an ak mal or setertei mal dies in their herd, people clean and decorate its skull and hang it at home to summon good fortune. Alternatively, people also put the skull on an obug-a (or ovoo sacrificial stone cairn) (see also Marchina et al. 2017). Worshipping herd animal skulls inside homes is not evident in the rest of northeast Asia. In Mongolia, horse skulls are generally placed on ovoo stone cairns at prominent points in the landscape. In the treatment of an akmal or setertei mal skull and related customary practices from Qinghai, we can find a similar understanding and use of the term 'fortune of herds', which is mal-un jayag-a [herd fate, destiny and fortune] and/or buyan [herd blessing, goodness and fortune].

In the above case, herd animals are regarded as able to generate reactions, or karmic consequences relating to mal-un jayag-a buyan. For example, an elder woman, Ibjin, from Barun Xiang (township), explained that on the eve day of the Lunar New Year they offer degeji (the first bits of food and drink, which should be offered to the most respected body) by putting small amounts in the

$8 \mathrm{Akmal}$ or 'elder animal' refers to uncastrated male animals, such as a stallion, bull, billy-goat or ram. In Mongolia, they are called etseg mal, which means a 'father animal'. 
mouth of the ak mal or setertei mal. ${ }^{9}$ More precisely, they offer degeji of gilaga (pressed and dried curd), shuumar (a mythic mountain made with barley meal with butter on the top and an ocean of dried curd underneath) and milk tea. The same ritual offerings are used during the New Year and other celebrations for elderly people and guests to show respect (B. Dulam 2006). In that sense, ak mal or setertei mal in the family herd receives the same level of respect as the elderly people and guests.

To consecrate (seterlekh) a herd animal member in the herd, which makes the animal inviolable and sacred, or an offering to deities to gain protection and prosperity (see also Fijn 2011: 43-7), is another common way to obtain a herd's fortune. The herd animal is no longer required to work physically, make material wealth for the family, or to be owned by the family. But the animal still lives with the rest of the herd. In Qinghai, such practices often can be seen as part of spiritual or religious customs, involving the worshipping of deities that protect livestock and their good fortune (see also B. Dulam 2006). Stépanoff et al. (2017) also refer to the practice of consecrating herd animals as an example of mutual protection between herds and herders, as a counter-example of complete human domination over herds. But, these practices of consecration do not make the herd animal entirely 'free' and 'autonomous'; instead the practices are a means to preserve the household fortune by consecrating and bringing the household into cosmological relation with deities, spirits and other beings. Therefore, the family cannot sell, lose, free or give away the consecrated herd animal, because it embodies and protects the herd's fortune. For herders, not having the consecrated herd animal present in the herd, if the animal dies suddenly or is stolen, is the equivalent of losing the fortune of the entire household.

Consequently, a herd's fortune is a complex moral concept that is manageable through consideration of all possible life circumstances, including physical and spiritual impacts on the well-being of the family. In the management of herd fortune, not only the human treatment of deities and local spirit masters are taken into account but herd-herder relations play an essential role with decisive importance. Families may have more or less herd fortune or misfortune due to their various pastoral practices and treatment of the livestock. But, what interests us in the practice of consecration is not the religious aspects, but the alternative economic aspects embodied in the concept of the herd as a source of fortune and wealth in Mongol pastoralist societies. Although herders do not often treat herd animals as consumable goods and products, these

9 Chimiddorj of Taij Nar Khoshuu, in Qinghai, also told a similar story. 
practices to obtain a herd's fortune are an alternative economic concern in herd-herder relations.

By examining herding practices for horses in Mongolia and the concept of livestock fortune and wealth, this article offers an extension to previous interpretations of human-animal relations in North Asia. Our findings illustrate that the concept of 'animal autonomy' does not feature in human-animal relations in these regions; rather the relations between households and multispecies herds are complex, dynamic and connected to a range of spiritual, social and work-related aspects. By putting forward a range of ethnographic examples, we aim to show that human-animal relations, or more precisely herd-herder relations, are not unchanging and should not be generalised. Rather, these relations, like all forms of social relations, undergo forms of transformation. In Mongolia today, certain households and regions face labour shortages due to households splitting roles to provide schooling for children (Ahearn \& Bumochir 2016) and due to increasing urbanisation. Thus, a lack of labour in the countryside, or in some cases a lack of experience and knowledge in relation to herding techniques, may contribute to horse herds becoming lost. This does not equate with the herd animal as being autonomous and beyond human management.

Our findings focus on three interconnected aspects of herding techniques in Mongolian cultural regions. The first is related to the consideration of horse agency and the role of the herder as a guardian and protector, to safeguard herds from hazards and by enabling horses to graze in a relaxed and serene way. The second finding relates specifically to horse-herding techniques and divisions of labour, and the physical requirements of family members who are involved in horse herding. From these examples, we see that certain individuals use their knowledge of the herd and the local environment to anticipate and direct herd movements and grazing patterns. Connected to this is the training of horses to go routinely to specific water sources or grazing areas commonly known as nutag. A mental map of horse-herd movement and routes is created by horse herders responsible for the horses. Thirdly, we can see the significance of 'malyn buyan khishig', which denotes a more cosmological relation between households and their livestock. In this sense, although herders do not treat livestock as 'cash crops' or 'units of productivity' for the sole purpose of making profits, herd animals are still considered to be live-stock, a key part of household wealth and prosperity, both spiritually and economically, and 
these concepts are not necessarily mutually exclusive. There is an increasing push for livestock intensification in Mongolia from policy makers, as well as the emerging discourse of livestock as sources of carbon emissions; the future of human-animal relations in the form of nomadic pastoralism remains an open question. Within these relations, we cannot deny the politics, which are certainly not restricted to the realm of human-human relations.

\section{Acknowledgements}

We would like to thank colleagues who have reviewed our paper and given comments. Special thanks to herders in Mongolia and China. Ichinkhorloo's field work in Khentii was partially funded by NSF Grant 174301.

\section{References}

Ahearn, A. \& D. Bumochir. 2016. Contradictions in schooling children among Mongolian pastoralists. Human Organization 75 (1): 87-96.

Badamkhatan, S. [1981] 2010. The way of life of co-operative herders, in D. Sneath \& C. Kaplonski (eds), The History of Mongolia: 1012-18. Folkestone: Global Oriental.

Balkhaajav, Ts. 2016. Khün aldryn gaikhamshig: Malchin udamt Mongol khün [Man is the wonder of fame: Mongols with herding origin]. Ulaanbaatar: Sodpress.

Beach, H. \& F. Stammler. 20o6. Human-animal relations in pastoralism. Nomadic Peoples 10(2): 6-29.

Bumochir, D. 2020. The State, Popular Mobilisation and Gold Mining in Mongolia: Shaping 'neoliberal' policies. London: UCL Press.

Bügd Nairamdakh Mongol Ard Ulsyn Ardyn Ikh Khural [The Great Khural (Parliament) of the Mongolian People's Republic]. 1992. Mongol Ulsyn Ündsen Khuuli [Constitution of Mongolia]. Assent January 13. http://www.legalinfo.mn/law/details/367.

Cassidy, R. \& M. Mullin. 2007. Where the Wild Things are Now: Domestication reconsidered. Oxford/New York: Berg.

Davaakhuu, B. (ed.). 2016. Mongol aduunii nevterkhii toli [Encyclopedia of Mongolian horses]. Ulaanbaatar: Mönkhiin Üseg.

Descola, P. 2013. Beyond Nature and Culture. Chicago (IL): University of Chicago Press.

Dulam, B. 2006. Respect and Power without Resistance: Investigations of Interpersonal Relations among Deed Mongols in Qinghai. PhD thesis, University of Cambridge.

Dulam, S. 2013. Mongol Soyol Irgenshliin Utga Tailal [Interpretation of Mongol culture and civilization]. Ulaanbaatar: Bit Press.

Empson, R. 2011. Harnessing Fortune: Personhood, memory and place in Mongolia. Oxford: Oxford University Press. 
Erdenetsogt, N. 1998. Mongolyn nü̈̈dliin mal aj akhui [Mongolian mobile pastoralism]. Ulaanbaatar: Urlakh Erdem.

Fijn, N. 2011. Living with Herds: Human-animal coexistence in Mongolia. Cambridge: Cambridge University Press.

Fraser, R. 2018. Motorcycles on the steppe: skill, social change, and new technologies in postsocialist northern Mongolia. Nomadic Peoples 22(2): 330-68.

Hamayon, R. 1990. La chasse à l'âme: esquisse d'une théorie du chamanisme sibérien [Hunting the Soul: Outlining a Theory of Siberian Shamanism]. Nanterre: Société d'ethnologie.

Heikkinen, H., O. Moilanen, M. Nuttall \& S. Sarkki. 2011. Managing predators, managing reindeer: contested conceptions of predator policies in Finland's southeast reindeer herding area. Polar Record 47(3): 218-30.

High, M.M. 2017. Fear and Fortune: Spirit worlds and emerging economies in the Mongolian gold rush. Ithaca (NY): Cornell University Press.

Horstkotte, T., T.Aa. Utsi, Å. Larsson-Blind, et al. 2011. Human-animal agency in reindeer management: Sámi herders' perspectives on vegetation dynamics under climate change. Ecosphere 8(9): 1-17.

Humphrey, C. \& H. Ujeed. 2012. Fortune in the wind: an impersonal subjectivity. Social Analysis 56(2): 152-67.

Ichinkhorloo, B. 2011. Herders' perception of good and bad pasture: in the case of complexity, in Accounting for Diversity in Mongolian History, Culture and Ecology (3rd Annual Conference of American Center for Mongolian Studies). Ulaanbaatar: ACMS. Unpublished conference presentation.

Ingold, T. 1994. From trust to domination: an alternative history of human animal relations, in A. Manning \& J. Serpell (eds), Animals and Human Society: Changing perspectives: 1-22. London: Routledge.

Luta. 1986. Degedü monggol-un aman zohiyal-du tushagdagsan monggol ündüsütenü zarim zang agali-iin tuhai [Some Mongol national customs revealed in Deed Mongol folklore]. Tsetsegtü Tsaidam 86(1): 91-6.

Marchina, C., S. Lepetz, C. Salicis \& J. Magail. 2017. The skull on the hill: Anthropological and osteological investigation of contemporary horse skull ritual practices in central Mongolia (Arkhangai province), Anthropozoologica 52(2), 171-83.

Nadelyaev, V.M., D.M. Nasilov, E.R. Tenishev \& A.M. Sherbak, 1969. Drevnetyurkskii Slovari [Ancient Turkic Dictionary]. Leningrad: Izdatel'stvo 'Nauka'.

Peemot, V.S. 2017. We eat whom we love: hippophagy among Tyvan herders. Inner Asia 19(1): $133-56$.

Philo, C. \& C. Wilbert. 200o. Animal spaces, beastly places: an introduction, in C. Philo \& C. Wilbert (eds), Animal Spaces, Beastly Places: New geographies of human-animal relations: $1-34$. London/New York: Routledge.

Sambuu, J. 1956. Malchdad ögökh zövlölgöö [Advice to herders]. Ulaanbaatar: Mal Aj Akhuin Yamny Khevlel. 
Soma, T. \& E. Schlecht. 2018. The relevance of herders' local ecological knowledge on coping with livestock losses during harsh winters in western Mongolia. Pastoralism 8(1): Article 3. https://doi.org/10.1186/s13570-017-0108-y.

Sonompel, T. 2012. Mongolyn mal aj akhuin tü̈̈khen khögjil, orchin üye [Historical development and the modernity of Mongolian pastoralism]. Ulaanbaatar: Möröödliin Gurvaljin.

Stépanoff, C., C. Marchina, C. Fossier \& N. Bureau. 2017. Animal autonomy and intermittent coexistences: North Asian modes of herding. Current Anthropology 58(1): $57-81$.

Steward, H. 2009. Animal agency. Inquiry 52(3): 217-31.

Takakura, H. 2015. Arctic Pastoralist Sakha: Ethnography of evolution and microadaptation in Siberia. Balwyn North (VIC): Trans Pacific.

Thrift, E. \& B. Ichinkhorloo. 2015. Management of $d z u d$ risk in Mongolia: Mutual aid and institutional interventions. Proceedings of the Trans-disciplinary Research Conference: Building Resilience of Mongolian Rangelands, Ulaanbaatar Mongolia, June 9-10: 136-41. Unpublished.

Tomorjav, M. \& N. Khurelbaatar. 2017. Mongol malchny erdem ukhaany deej orshiv [Masterpiece of Mongolian herders' knowledge and intelligence]. Ulaanbaatar: TEPE Print.

Tserenkhand, G. 2005. Mongolchuud: Ugsaa soyol, zan zanshil II Boti (Mongolians: Ethnic culture and customs Vol. 2). Ulaanbaatar: Admon Khevleliin Gazar.

Vitebsky, P. \& A. Alekseyev. 2014. What is a reindeer? Indigenous perspectives from Northeast Siberia. Polar Record 51(4): 413-21.

Waddington, C.H. 1974. Horse brands of the Mongolians: a system of signs in a nomadic culture. American Ethnologist 1(3): 471-88. 